\title{
Spor Bilimleri Fakültesi Öğrencilerinin Bilgisayar Kullanma Becerileri ve Teknolojiye Yönelik Tutumlarının İncelenmesi
}

\author{
Hanifi ÜZÜM ${ }^{1}$ \\ Mehmet ASLAN ${ }^{2}$ \\ Merve ŞİMŞEK ${ }^{5}$
}

\author{
Ahmet Berat YÜKSEL ${ }^{3} \quad$ Mustafa YALDIZ ${ }^{4}$ \\ Muzaffer Emir OPAK ${ }^{6}$
}

$\ddot{\mathbf{O} z}$

$\mathrm{Bu}$ çalışmanın amacı, spor bilimleri fakültesi öğrencilerinin bilgisayar kullanma becerileri ve teknolojiye yönelik tutumlarını incelemektir. Genel tarama modellerinden biri olan anlık tarama yaklaşımı ve ilişkisel tarama modeline göre dizayn edilen çalışmanın örneklem grubunu 2019/20 öğretim yıll güz döneminde Bolu Abant Baysal Üniversitesi Spor Bilimleri Fakültesi’nde okuyan 348 (145 Kadın, 203 Erkek) öğrenci oluşturmuştur. Araştırmada, veri toplama aracı olarak "Bilgisayar Kullanma Becerileri ve Bilgisayarlara Yönelik Tutum Ölçeği” kullanılmıştır. Verilerin analizinde parametrik testlerden ikili karşılaşıırmalarda bağımsız örneklemler T-test, çoklu karşılaştırmalarda tek yönlü varyans analizi One Way Anova-test, ilişki karşılaştırmalarında ise Pearson korelasyon analizinden yararlanılmıştır. Çalışmanın sonuçları genel olarak değerlendirildiğinde, 1. Sınıf ile 3. Sınıf öğrencileri arasında 3. Sınıflar lehine bilgisayar kullanma becerileri arasında anlamlı fark bulunmuştur. Teknoloji kullanımında Antrenörlük bölümü öğrencileri ve Spor Yöneticiliği bölümü öğrencileri arasında Antrenörlük öğrencileri lehine anlamlı bir fark bulunmuştur. Elde edilen bu sonuçlara göre spor bilimleri fakültesi öğrencilerinin bilgisayar kullanma becerileri ve teknolojiye yönelik tutumlarının geliştirilmesi, fakültedeki mevcut olanakların iyileştirilerek, okullardaki kullanım düzeylerinin gerekli olan yeterlik düzeyinde geliştirilmesinin gerekli olduğu düşünülmektedir.

Anahtar Kelimeler: Teknoloji, Teknoloji Kullanımı, Bilgisayar, Spor Bilimleri.

\section{The Study of Computer Skills and Attitudes Towards Technology of Sports Science Faculty Students}

\begin{abstract}
The aim of this study is to examine computer related skills and attitudes of the students of the faculty of sport science, towards technology. The sample group of the study, which was designed according to the instant scanning approach and relational scanning model, which is one of the general screening models, consisted of 348 (145 Female, 203 Male) students studying at Bolu Abant Baysal University Faculty of Sport Sciences in the fall semester of 2019/20 academic year. In the study, "Computer Using Skills and Attitude Scale Towards Computers" was used as data collection tool. In the analysis of the data, independent samples T-test was used for paired comparisons among parametric tests, one-way analysis of variance One Way Anova-test was used in

\footnotetext{
6Sorumlu Yazar: Abant İzzet Baysal Üniversitesi, Spor Bilimleri Fakültesi, Bolu-Türkiye, emirorak@hotmail.com, https://orcid.org/0000-0001-5599-2447

${ }^{1}$ Abant İzzet Baysal Üniversitesi, Spor Bilimleri Fakültesi, Bolu-Türkiye, uzum_h@ibu.edu.tr https://orcid.org/0000-0002-0555-266X

${ }^{2}$ Abant İzzet Baysal Üniversitesi, Spor Bilimleri Fakültesi, Bolu-Türkiye, mehmetaslann46@gmail.com, https://orcid.org/0000-0003-0600-3168

${ }^{3}$ Abant İzzet Baysal Üniversitesi, Spor Bilimleri Fakültesi, Bolu-Türkiye, beratyuksell4@ hotmail.com, https://orcid.org/0000-0002-5633-9092

${ }^{4}$ Abant İzzet Baysal Üniversitesi, Spor Bilimleri Fakültesi, Bolu-Türkiye, yaldiz.mustafa81@ @mail.com,

${ }^{5}$ Abant İzzet Baysal Üniversitesi, Spor Bilimleri Fakültesi, Bolu-Türkiye, mervesimsekts@ gmail.com, https://orcid.org/0000-0002-5149-873X
} 
multiple comparisons, and Pearson correlation analysis was used for correlation comparisons.According to these results, it is considered essential to improve the computer use skills and attitudes towards technology of the students of the faculty of sports sciences, to improve the existing facilities in the faculty and to raise the level of computer use in schools to a sufficient level.

Keywords: Technology, Usage of Technology, Computers, Sport Sciences.

\section{GíRIŞ}

Bilgi, eğitimin en temel yapı taşı olarak görülmektedir. Ayrıca bilgi, teknolojik ve bilimsel değişimin de önemli bir bileşenidir ve tüm bireylerin yaşamını şekillendirmesinde önemli bir rol oynamaktadır. İnsanlık, günümüz bilgi ve teknoloji çağına gelene kadarki süreçte en eski bilgi teknolojileri olan; kitaplar ve basılı yayınlar aracılığıla bilgi edinimi sağlamaktaydı (Çavaş, Kışla ve Twining, 2004). Bilginin hizla artmas sonucunda bilgiye ulaşma yollarının da kendiliğinden yön değiştirdiği gözlemlenmektedir. İçinde bulunulan çağın önceliği olarak bilgiyi fiziki materyallerden araştırmak ve takip etmek yerine artık sanal olarak kullanılan kütüphanelerden, veri tabanlarından ve bunun gibi kaynaklara internet üzerinden ulaşmak artık daha kolay ve önemli bir hale gelmiştir (Aksüt, 2005).

Günlük yaşam içerisinde varlığını sürdüren ve sürdürmeye hizla devam eden kavramlardan biri de bilgi teknolojileridir. Bilgi teknolojilerine bakıldığında; bilgi ve düşüncenin akışını hızlı bir şekilde önümüze getiren teknolojik araçlara (radyo, televizyon, video, DVD, telefon sabit ve mobil), uydu sistemleri, bilgisayar ve network donanımı ve yazılımı, ayrıca, bu teknolojiler tarafindan sağlanan donanım ve hizmetlere (videokonferans ve elektronik posta gibi) verilen isimdir (Yücel ve Devecioğlu, 2011). Bu teknolojilerin gelişmesiyle insanlar teknolojiyi günlük yaşantılarında daha fazla kullanmaya başlamış ve hayatlarındaki teknoloji kullanımının yeri artık yadsınamaz derecede fazlalaşmıştır (Akkoyunlu, 1995). Teknolojinin varoluşundan beri bilgilerin kişilerce daha kolay paylaşılabilmesi, işlenip sunulabilmesi yönünden bakılırsa insanlar artık daha kolay bilgilere ulaşabilmekte ve bunun sonucunda da birçok alanda teknolojinin insanlara daha faydalı olduğu görülebilmektedir. Böylece insanlar artık bilginin saklanması, paylaşılması, işlenmesi alanında teknolojiden yardım alarak bilgi aktarımının daha hızlı ve büyük kolaylıklar getirmesi sebebiyle sektörde bilgi teknolojilerinin yaygın olarak kullanılmasının oranlarını sürekli olarak arttırmaktadırlar (Yüksel, 2005). Yine de bilgisayarın yaygın olarak kullanımının artmasının yanında bu teknolojinin kullanımının yeterli derecede verimli olmasını sağlamak için kişilerin bu teknolojik gelişmelere ayak uydurması gerekmekte ve bu alanda bilgi ve becerileri öğrenip bunları uygulamaya geçirmesi gerekmektedir ki daha verimli sonuçlar elde edilebilsin (Krueger, Hansen ve Smaldino, 2000).

Bilgi teknolojilerinin kullanılmasının önemini anlayan ülkelerde, özellikle ilk ve orta öğretim seviyelerinde eğitim kurumlarında bilgi teknolojilerinin etkin kullanımı konularında 1980'lerden itibaren devlet destekli uygulamalara başlanmıştır (Visscher, Wild, Smith ve Newton, 2003). Teknoloji ve yönetim anlayışının gelişmesinde, bilgiye sahip olmak önemli olsa da tek başına yeterli değildir. Sahip olduğumuz bilginin nerede ve nasıl kullanılması gerektiğinin bilincinde olmak bilgiye sahip olmaktan daha önemlidir (Tecim ve Gökşen, 2009). Kişiler, bilgi ve iletişim teknolojilerini kullanarak gereksinim duyduğu bilgiye ulaşabilen, elde ettiği bu bilgiyi araştırabilen ve değerlendirme yapabilen bir özellikte olmalıdır. Bu açıdan; gelecek nesillerin, bilgi ve iletişim teknolojilerinden en etkili şekilde yararlanmaları ve eğitim almaları önemlidir (Özmusul, 2008).

Teknolojik gelişmeler yaşamdaki her alanda etkilerini göstermektedir. Beden eğitimi ve spor alanında da etkileri göz ard1 edilememektedir. Spor alanındaki büyüme ve sürekli artmakta olan rekabet ortamını da ele aldığımızda, bu alanda sporcuların eğitim ve performans düzeylerini arttırmak için birçok bilimsel ve teknolojik çalışma yapılmaktadır (Özen, Güllü ve Uğraş, 2016). 
Eğitimciler arasında, öğrenme sürecine uygun teknoloji entegrasyonunun öğrenci katılımı ve başarısında önemli gelişmelere katkıda bulunduğu ve beden eğitimindeki bireysel öğrencilerin öğrenme ihtiyaçlarını karşılama potansiyeli sunduğu konusunda bir fikir birliği vardır. Yapılan çalışmalar göz önünde bulundurulduğunda kullanılan araçlar ve sistemler teknolojik gelişmelere göre tasarlanıp üretilmektedir (Palao, Hastie, Ortega ve Cruz, 2015).

Spor biliminin ve teknolojinin ortak olarak buluştuğu bir nokta belirleyecek olursak bu asıl noktaya spor teknolojisi adını verebiliriz. Spor teknolojisinin hedefi sporun profesyonelleşerek ilerlemesi, spor organizasyonları, bu organizasyonların yönetilmesi, spor örgütlerinin işleyişi ve yönetimi, sporcuların yetiştirilmesi gibi pek çok alana hizmet etmesi gerekli diyebiliriz. Son dönemde gelişen sporun teknolojik unsurları alana önemli bir katk1 sağlamaktadır. Spor teknolojisi kavramından yola çıkarak bir araştırma yapıldığında spor sektörü içerisinde teknolojik gelişmelerin arttığını ve bu gelişmeler aracılığıyla sporun seyir zevkinde de artış olduğu görülmektedir. Sadece seyir zevki açısından değil sporu yöneten kurumların, büyük ve küçük spor organizasyonlarının yapılması ve bu organizasyonların yönetilmesi, denetlenmesi konularında da gelişmeler olduğu görülmektedir (Tosun-Tunç ve Sevilmiş, 2019).

Spor teknolojisinin beraberinde getirdiği yeniliklere bakacak olursak;

- Olimpiyat oyunları, dünya şampiyonaları, ligler, spor etkinlikleri gibi organizasyonların yapıldığı alanlarda açılış ve kapanış seremonilerinde kullanılan görsel sunumlar,

- Sporcularin antrenman ve maç esnasında kullandıkları kıyafet, araç ve gereçler,

- Hakemlerin karar vermesine yardıme olmak amaciyla üretilen sistemler (VAR, Hawk-Eye, Challenge System $\mathrm{vb})$,
- Antrenörlerin kullandığı performans geliştirme yazılımları,

- Spor federasyonları ve kulüplerin kullandığ 1 sistemleri (Paso Lig vb.),

- Spor kurumlarında kullanılan E-imza, bulut depolama vb. sanal bellekler,

gelişmeleri kısaca bu şekilde tanımlayabiliriz (Devecioğlu ve Şimşek, 2018), (Yücel ve Devecioğlu, 2012).

Yukarıda sıralanmış olan spor ile ilgili teknolojik araç ve gereçlerin sürekli olarak gelişmesinden dolayı bu teknolojileri kullanan bireylerin, teknolojik gelişmeleri yakından takip etmesi ve verimli bir şekilde kullanabilmesi oldukça önemlidir.

$\mathrm{Bu}$ nedenle ileride geleceğin herhangi bir spor örgütü çalışanı (spor yöneticisi, uzman, personel) olacak olan öğrenciler üzerinde bir araştırma yapılma ihtiyacı ortaya çıkmıştır. Spor örgütü çalışanı olmaya aday olan öğrencilerin yukarıda bahsettiğimiz teknolojik gelişmelerden haberdar olup olmadıkları, teknolojik gelişmelere adapte olabilme durumları, yaşamlarında teknolojik aletleri kullanım düzeyleri ölçülerek çıkan sonuçlara göre spor eğitimi veren yükseköğretim kurumlarında teknoloji ile ilgili derslerin durumu, okullarda daha fazla teknolojik eğitime ihtiyaç olup olmadığı sorularına yanıt aranmıştır. Topladığımız veriler dâhilinde spor bilimleri fakültelerinde ve yüksekokullarında öğrenim gören öğrencilerin gelişimini daha doğru bir şekilde desteklemek, eğitimin kalitesini artırmak, teknolojik yeterlilikleri arttırabilmek böylece yetişmekte olan spor uzmanlarını, öğretmenleri, antrenörleri kısaca sporla bağlantısı olan her bireyin mevcut durumlarını anket yöntemiyle ölçülerek ileride bu ögrencilerin gelişimine destek olabilecek bir araştırmanın yapılması düşünülmüştür

\section{Araştırmanın Amacı \\ $\mathrm{Bu}$ noktadan hareketle yapılan çalışmada, Bolu Abant İzzet Baysal Üniversitesi Spor Bilimleri Fakültesi öğrencilerinin teknoloji kullanım düzeylerinin; Mevcut Olanaklar, Bilgisayar Kullanma Becerisi, Okullarda Bilgisayar Kullanma Düzeyi boyutları kapsamında incelenmesi hedeflenmiştir.}




\section{YÖNTEM}

Araştırma, genel tarama modellerinden biri olan anlık tarama yaklaşımı ve ilişkisel tarama modeline göre dizayn edilmiştir. Karşılaştırma yolu ile ilişki belirlemede en az (bağımlı ve bağımsız) iki değişken vardır. Bunlardan birine göre gruplar oluşturulur, öteki değişkene göre aralarında bir farklılaşma olup olmadığına bakılır (Karasar, 2015).

\section{Araştırma Örneklem Grubu}

$\mathrm{Bu}$ araştırmanın çalışma gurubu Bolu Abant İzzet Baysal Üniversitesi Spor Bilimleri Fakültesi bünyesinde bulunan öğrencilerden "Tesadüfi Örnekleme Yöntemi” ile seçilen 145 kadın, 203 erkek olmak üzere toplam 348 katılımcıdan oluşmuştur. Yapılan bu çalışmada "Yükseköğretim Kurumları Bilimsel Araştırma ve Yayın Etiği Yönergesi" kapsamında uyulması belirtilen tüm kurallara uyulmuştur. Yönergenin ikinci bölümü olan "Bilimsel Araştırma ve Yayın Etiğine Aykırı Eylemler" başlığ 1 altında belirtilen eylemlerden hiçbiri gerçekleştirilmemiştir.

Ayrıca bu çalışma için Bolu Abant İzzet Baysal Üniversitesi / Sosyal Bilimlerde İnsan Araştırmaları Etik Kurulundan 21.01.2020 tarih ve 2020/14 say1 numarası ile etik kurul onayı alınmıştır.

\section{Veri Toplama Araçları}

Çalışma da: Yeşilyurt ve Gül tarafindan (2007) geliştirilen Bilgisayar kullanma becerileri ve bilgisayara yönelik tutum ölçeği kullanılmıştır. Ölçek 3 alt boyuttan (mevcut olanaklar, bilgisayar kullanım becerisi, okullardaki kullanım düzeyi) ve 26 maddeden oluşmaktadır. Buna göre ölçeğin alt boyutlarının iç tutarlılık katsayıları: Mevcut Olanaklar alt boyutu; 0,90 Bilgisayar Kullanım Becerisi alt boyutu; 0,78, Okullardaki Kullanım Düzeyi alt boyutu; 0,68 'dir. Ölçeğin toplam iç tutarlılık katsayısı; 0,91 'dir.

Ölçek beşli likert tipine göre dizayn edilmiştir (Kesinlikle katılmiyorum=1), $($ Katılmıorum=2), $($ Kismen Kat1lyorum=3), $($ Kat1lyorum=4), $($ Kesinlikle Katılıorum=5). Ölçekte olumsuz ifade yer almamaktadır.
Ölçek alt boyutlarına ilişkin iç tutarlılık katsayıları bu çalışma için incelendiğinde Mevcut Olanaklar=0,65, Bilgisayar Kullanma Becerisi $=0,76$ ve Okullardaki Kullanım Düzeyi $=0,58$ olarak hesaplanmıştır. Ölçeğin toplam iç tutarlılık katsayısı ise 0,83 olarak bulunmuştur.

\section{Verilerin Toplanmast ve Analizi}

Araştırmada elde edilen veriler SPSS programı aracılığıyla bilgisayar ortamında analiz edilmiştir. Verilerin çözümlenmesi için yapılan normallik analizi dağılımı sonucunda skewness ve kurtosis değerlerinin +3 ile -3 arasında olduğu görülmüştür (Huck,2008). Bu nedenle toplanan verilere parametrik testlerden ikili karşılaştırmalarda bağımsız örneklemler T-test, çoklu karşılaştırmalarda tek yönlü varyans analizi One Way Anova-test, ilişki karşılaş̧ırmalarında ise Pearson korelasyon analizi kullanılmıştır.

\section{BULGULAR}

Tablo 1. Tanımlayıcı İstatistikler

\begin{tabular}{llll}
\hline & & $\mathrm{f}$ & $\%$ \\
\hline \multirow{5}{*}{ Bölüm } & $\begin{array}{l}\text { Spor Yöneticiliği } \\
\text { (SYÖ) }\end{array}$ & 143 & 41,1 \\
\cline { 2 - 4 } & $\begin{array}{l}\text { Beden Eğitimi } \\
\text { Öğretmenliği } \\
\text { (BEÖ) }\end{array}$ & 89 & 25,6 \\
& $\begin{array}{l}\text { Antrenörlük } \\
\text { Eğitimi (ANE) }\end{array}$ & 116 & 33,3 \\
\hline Cinsiyet & Kadın & 145 & 41,7 \\
\cline { 2 - 4 } & Erkek & 203 & 58,3 \\
\hline Sinıf & 1.Sınıf & 126 & 36,2 \\
\cline { 2 - 4 } & 2.Sınıf & 59 & 17,0 \\
\cline { 2 - 4 } & 3.Sınıf & 119 & 34,2 \\
\cline { 2 - 4 } & 4.Sınıf & 44 & 12,6 \\
\hline Eğitim & Evet & 94 & 27,0 \\
& Hayır & 254 & 73,0 \\
\hline Toplam & & 348 & 100 \\
\hline
\end{tabular}

Tablo 2 incelendiğinde katılımcıların bilgisayar kullanımı ve okullardaki kullanım düzeyi boyutlarında ortalamanın üzerinde bir puana sahip oldukları gözükmektedir. 
Tablo 2. Ölçek Alt Boyutlarının Ortalama ve Yaygınlık Ölçüleri

\begin{tabular}{lll}
\hline Alt Boyutlar & $\overline{\mathbf{x}}$ & $\mathrm{S}$ \\
& & \\
\hline Mevcut Olanaklar & 2,79 & 0,54 \\
\hline Bilgisayar Kullanma Becerisi & 3,14 & 0,80 \\
\hline Okullardaki Kullanım Düzeyi & 3,07 & \\
\hline
\end{tabular}

Tablo 3. Cinsiyet Değiş̧kenine Bilgisayar Kullanma Becerileri ve Teknolojiye Yönelik Tutumların İncelenmesi Ölçeği Alt Boyutlarına İlişkin Farklar

\begin{tabular}{llccccc}
\hline Alt Boyutlar & Cinsiyet & $\mathrm{N}$ & $\overline{\mathbf{x}}$ & $\mathrm{S}$ & $\mathrm{t}$ & $\mathrm{p}$ \\
\hline Mevcut Olanaklar & Kadın & 145 & 2,73 & 0,53 & & \\
& Erkek & 203 & 2,83 & 0,55 & $-1,754$ & 0,08 \\
& Kadın & 145 & 3,11 & 0,76 & & \\
Bilgisayar & Erkek & 203 & 3,16 & 0,83 &,- 776 & 0,43 \\
Kullanma Becerisi & & & & & & \\
& Kadın & 145 & 3,11 & 0,76 & & \\
Okullardaki & Erkek & 203 & 3,04 & 0,70 & 0,908 & 0,36 \\
Kullanım Düzeyi & & & & & & \\
\hline
\end{tabular}

Tablo 3 incelendiğinde; Bilgisayar Kullanma Becerileri ve Teknolojiye Yönelik Tutumların İncelenmesi ölçeğinin alt boyutları ile cinsiyet

Tablo 4. Eğitim Alma Durumu Değişkenine Göre Bilgisayar Kullanma Becerileri ve Teknolojiye Yönelik Tutumların İncelenmesi Ölçeği Alt Boyutlarına İlişkin Farklar

\begin{tabular}{llllllll}
\hline Alt Boyutlar & $\begin{array}{l}\text { Eğitim } \\
\text { Durumu }\end{array}$ & Alma & $\mathrm{N}$ & $\overline{\mathbf{x}}$ & $\mathrm{S}$ & $\mathrm{t}$ & $\mathrm{p}$ \\
\hline $\begin{array}{l}\text { Mevcut } \\
\text { Olanaklar }\end{array}$ & Evet & 94 & 2,86 & 0,56 & & \\
Hayır & 254 & 2,76 & 0,54 & 1,42 & 0,15 \\
$\begin{array}{l}\text { Bilgisayar } \\
\text { Kullanma } \\
\text { Becerisi }\end{array}$ & Evet & 94 & 3,26 & 0,82 & & \\
$\begin{array}{l}\text { Okullardaki } \\
\text { Kullanım }\end{array}$ & Evet & 254 & 3,02 & 0,77 & 2,58 & 0,01 \\
Düzeyi & Hayır & 94 & 3,14 & 0,81 & & \\
& & 254 & 3,04 & 0,72 & 1,12 & 0,26
\end{tabular}

değişkeni arasında istatistiksel olarak anlamlı bir farklılık bulunmamıştır ( $\mathrm{p}>0,05)$. 
Tablo 4 incelendiğinde; eğitim alma durumu değişkenine göre Bilgisayar kullanma becerisi alt boyutunda anlamlı fark bulunmaktadır
( $<<0,05)$. Mevcut Olanaklar ve Okullardaki kullanım düzeyi alt boyutlarında ise anlamlı farkl11ık bulunmamaktadır $(\mathrm{p}>0,05)$.

Tablo 5. Bölüm Değişkenine Göre Bilgisayar Kullanma Becerileri Ve Teknolojiye Yönelik Tutumların İncelenmesi Ölçeği Altboyutlarına İlişkin Farklar

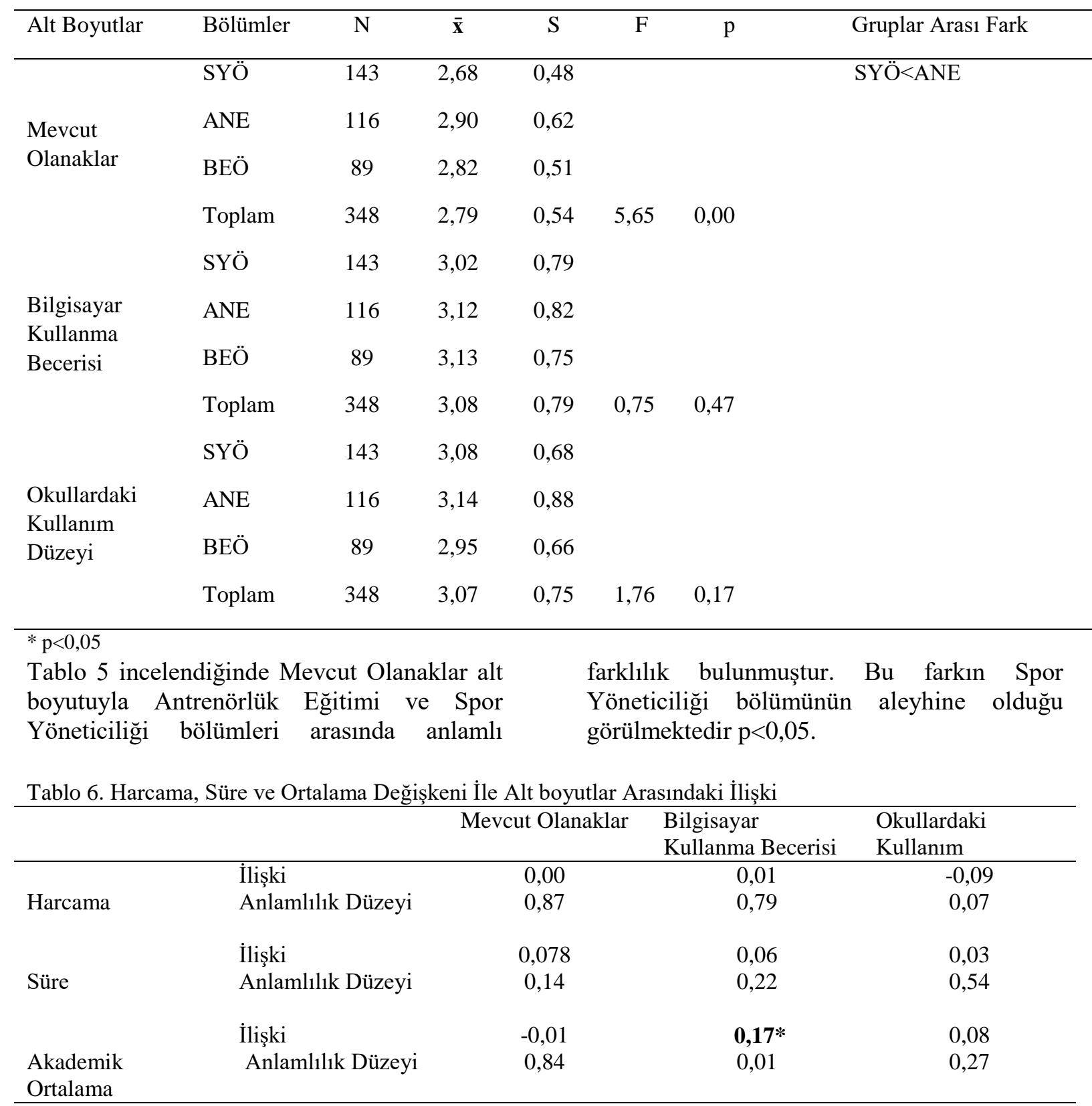

Tablo 6 incelendiğinde, Bilgisayar Kullanma Becerisi alt boyutu ile Akademik Ortalama değişkeni arasında pozitif yönde düşük düzeyde anlamlı bir ilişki bulunmuştur. $\mathrm{P}<0,05$. 
Üzüm, H., Aslan, M., Yüksel, A.B., Yaldız, M., Şimşek, M., Opak, M.E./ Spor Bilimleri Fakültesi Öğrencilerinin Bilgisayar Kullanma Becerileri ve Teknolojiye Yönelik Tutumlarının İncelenmesi

Tablo 7. Sınıf Değişkenine Göre Bilgisayar Kullanma Becerileri ve Teknolojiye Yönelik Tutumların İncelenmesi Ölçeği Alt boyutlarına İlişkin Farklar

\begin{tabular}{|c|c|c|c|c|c|c|c|}
\hline Alt Boyutlar & Siniflar & $\mathrm{N}$ & $\overline{\overline{\mathbf{x}}}$ & $S$ & $\mathrm{~F}$ & $\mathrm{p}$ & Gruplar Arası Fark \\
\hline \multirow{5}{*}{$\begin{array}{l}\text { Mevcut } \\
\text { Olanaklar }\end{array}$} & 1. Sinif & 126 & 2,69 & 0,56 & & & \multirow{15}{*}{ 3. Sinıf $>1$. Sinıf } \\
\hline & 2. Sinif & 59 & 2,85 & 0,59 & & & \\
\hline & 3. Sinıf & 119 & 2,83 & 0,45 & & & \\
\hline & 4. Sinif & 44 & 2,90 & 0,63 & & & \\
\hline & Toplam & 348 & 2,79 & 0,54 & 2,49 & 0,06 & \\
\hline \multirow{5}{*}{$\begin{array}{l}\text { Bilgisayar } \\
\text { Kullanma } \\
\text { Becerisi }\end{array}$} & 1. Sinif & 126 & 2,93 & 0,81 & & & \\
\hline & 2. Sinif & 59 & 3,11 & 0,79 & & & \\
\hline & 3. Sinif & 119 & 3,20 & 0,74 & & & \\
\hline & 4. Sinıf & 44 & 3,16 & 0,82 & & & \\
\hline & Toplam & 348 & 3,08 & 0,79 & 2,76 & 0,04 & \\
\hline \multirow{5}{*}{$\begin{array}{l}\text { Okullardaki } \\
\text { Kullanım } \\
\text { Düzeyi }\end{array}$} & 1. Sinif & 126 & 2,97 & 0,74 & & & \\
\hline & 2. Sinıf & 59 & 3,11 & 0,72 & & & \\
\hline & 3. Sinıf & 119 & 3,11 & 0,73 & & & \\
\hline & 4. Sinif & 44 & 3,17 & 0,87 & & & \\
\hline & Toplam & 348 & 3,07 & 0,75 & 1,20 & 0,30 & \\
\hline
\end{tabular}

Tablo 7 incelendiğinde Bilgisayar Kullanma Becerisi alt boyutuyla 1. Sinif ve 3. Sinıflar arasında anlamlı farklılık bulunmuştur. $\mathrm{Bu}$

\section{TARTIŞMA ve SONUÇ}

Yaşadığımız bilgi çağında eleştirel, yaratıcı düşünen ve bilgiye ulaşabilen bireylere gereksinim bulunmaktadır. Günümüzde, teknolojideki hızlı değişimler ve gelişmelerle birlikte her türlü bilgiye kolaylıkla ulaşabilmek mümkündür. $\mathrm{Bu}$ bağlamda, teknolojik gelişmelerden olan bilgisayarın, bilginin yayılmasında ve paylaşıılmasındaki önemi yadsınamaz bir gerçektir. Bilim ve teknolojideki hızlı değişimler ve gelişmeler farkın 3. sinıfların lehine olduğu görülmektedir $\mathrm{p}<0,05$.

eğitim alanında yeni olanaklar sunmaktadır (Demirli ve Dikici, 2003).

$\mathrm{Bu}$ olanaklar sayesinde, öğretmen adaylarının, etkili ve verimli öğrenme ortamları ile birleştirilip, bütünleştirilmeleri ve toplumun kendisini daha ilerletebilmesi için geliştirilmiş eğitim sistemi ile birlikte, ilerleyen teknolojinin sunduğu olanakları kullanabilmeleri büyük önem taşımaktadır. Spor Bilimleri Fakültesi öğrencilerinin bilgisayar kullanma becerileri ve teknolojiye yönelik tutumları incelendiğinde bilgisayar teknolojilerini etkili bir biçimde 
kullanabilmeleri için gerekli olan bilgi ve becerilerinin kazandırılmasına ve bilgisayar kullanıma ilişkin tutumlarının olumlu yönde geliştirilmesine ilișkin çalışmaların ağırlık kazanması gerektiği düşünülmektedir. Çünkü Spor Bilimleri Fakültesi öğrencilerinin, bilgisayar kullanımlarına ilișkin tutumlarının incelenerek, gerekli eksiklik ve/veya önlemlerin alınmasının, bilgisayarın eğitim ortamında daha sağlıklı bir şekilde planlanıp kullanılabilmesine olanak sağlayacağını düşündürmektedir (Uşun, 2013).

$\mathrm{Bu}$ nedenle yapılan bu çalışmada, Spor Bilimleri Fakültesi öğrencilerinin bilgisayar kullanma becerileri ve bilgisayarlara yönelik tutumlarının bazı değişkenler açısıından incelenmesi amaçlanmıştır. Spor Bilimleri Fakültesi öğrencilerinin bilgisayar kullanma becerileri ve teknolojiye yönelik tutumları incelendiğinde katılımcıların bilgisayar kullanma becerisi boyutu ortalamasinın $(\bar{x}=3,08)$ mevcut olanaklar $(\bar{x}=2,79)$ ve okullardaki kullanım düzeyine $(\bar{x}=3,07)$ göre daha yüksek olduğu bulunmuştur (Tablo 2). Çakmak ve Yalçın (2013) öğrencilerin teknoloji kullanımı alışkanlıkları üzerine yapmış oldukları çalışmada, gençlerin teknolojik gelişmelere hızlı bir şekilde uyum sağladığını ve teknolojik araçlar üzerinden bilgi kullanımı ve bilgiye erişimde hızlı bir şekilde değişim gösterebildiklerini vurgulamışlardır. $\mathrm{Bu}$ sonuçlara dayanarak Spor Bilimleri Fakültesinde okuyan öğrencilerin teknoloji kullanım becerilerinin yüksek ve onlara okullarında sunulan teknolojik imkanların yeterli olduğunu söyleyebiliriz.

Araştırmanın bir diğer bulgusunda Bilgisayar Kullanma Becerileri ve Teknolojiye Yönelik Tutumların İncelenmesi ölçeğinin alt boyutları ile cinsiyet değişkeni arasında istatistiksel olarak $(\mathrm{p}>0,05)$ düzeyinde anlamlı bir farklılık bulunmamıstır (Tablo 3). Bu sonuca dayanarak, spor bilimleri fakültesi öğrencilerinin bilgisayar kullanma becerileri ve bilgisayarlara yönelik tutumlarının cinsiyet değişkenine göre farklılaşmadığını söyleyebiliriz. Günümüzde, öğrencilerin bilgisayara sahip olma ve bilgisayar kullanım durumlarının giderek artıyor olmasının cinsiyete bağlı farklılığın giderek azaldığının bir göstergesi olarak kabul edilebilir. $\mathrm{Bu}$ bulguya ilişkin, literatürde de benzer sonuçlar bulunmaktadır (Yuen ve Ma, 2002; Shapkaye ve Ferrari, 2003; Çelik ve Bindak, 2005; Cantürk, Günhan, Başer ve Yavuz, 2008; Cevik, 2015; Hunt ve Bohlin, 1993; Aycan ve Üzüm, 2020).

Araştırmanın bir diğer bulgusunda Eğitim alma durumu değişkenine göre Bilgisayar Kullanma Becerisi alt boyutunda anlamlı fark bulunmaktadır $(p<0,05)$. $\mathrm{Bu}$ sonuca göre bilgisayar eğitimi alan kişilerin daha önce hiç bilgisayar eğitimi almayan kişilere göre bilgisayar kullanma becerilerinin daha yüksek olduğu söylenebilir (Tablo 4). Öğrencilerin eğitiminde, teknolojilerin kolay öğrenilir ve kullanılır olmasının öğrenme-öğretme sürecinde verimliliği arttıracağı bir gerçektir. $\mathrm{Bu}$ nedenle üniversitelerde, teknolojiyi kullanma konusunda olumlu fikirlerin yaygınlaşması, söz konusu eğitimlerin verilmesi teknolojilerinin kullanılması, motivasyonun artmasına da yardımcı olacaktır (Bozcan, 2010).

Bölüm değişkenine göre; Antrenörlük Eğitimi ve Spor Yöneticiliği bölümleri arasında mevcut olanaklar alt boyutunda Spor Yöneticiliği bölümünün aleyhine $\mathrm{p}<0,05$ düzeyinde anlamlı farklılık bulunmuştur (Tablo 5). Bu sonuca göre; antrenörlük eğitimi alan kişilerin, spor yöneticiliği bölümü ögrencilerine göre mevcut olanakları daha verimli kullandığını söyleyebiliriz. Oysaki hemen hemen tüm ülkelerde, "her okula bir bilgisayar laboratuvarı" (veya her sinifa bir bilgisayar) okulların hizmetine sunulmaktadır (Akpinar, 2005).

Söz konusu farkın antrenörlük eğitimi öğrencilerinin mesleki eğitimleri gereği ölçüm ve test yapabilecekleri cihazların kullanımında bilgisayar ve bilgisayar ile koordineli çalışan donanımları diğer bölümlere göre daha fazla kullanmalarından kaynaklandığı söylenebilir. Spor yöneticiliği öğrencilerinin, bilgisayarları eğitimleri boyunca kullanım yeterliklerinin yeterince sağlanamamış olduğunu ve bunun için de bilgisayarların derslerdeki kullanım niteliklerinin gözden geçirilerek bu konudaki eksikliklerin ortaya çıkarılması gerektiği söylenebilir. 
Araştırmanın bir diğer bulgusunda Bilgisayar Kullanma Becerisi alt boyutuyla 1 . Sinıf ve 3 . Siniflar arasında $(\mathrm{p}<0,05)$ düzeyinde anlamlı farkl1l1k tespit edilmiştir (Tablo 7). Bu fark 3. sinıfların lehinedir. $\mathrm{Bu}$ sonuca göre; Müfredatlar dikkate alındığında bölümlerin alana dair bilgisayar becerilerini fazlaca kullandıkları dönemin 3 sinıf ve sonrasını kapsamasından kaynaklanabilir. Konu ile ilgili literatür incelendiğinde; Som ve Kurt (2012) öğrencilerin sınıf düzeyleri ile teknoloji kullanımı arasında anlamlı bir fark olduğu sonucuna ulaşmış ve sınıf düzeyi arttıkça medya okuryazarlığının da arttığını vurgulamışlardır.

Araştırmanın bir diğer bulgusunda Alt boyutlar ile Harcama değişkeni arasında $(\mathrm{P}>0,05) \quad$ düzeyinde anlamlı bir ilişki saptanmamıştır. $\mathrm{Bu}$ sonuca göre bireylerin harcama miktarları değişkenlik gösterse de alt boyutlara herhangi bir etkisi olmamıştır (Tablo 6). Çünkü; günümüzde üniversite öğrencileri için bilișim teknolojileri harcamaları bir ihtiyaç haline gelerek lüks harcamalar sınıfindan çıkmıştır (Aktaş, Tuncer ve Kıran, 2020).

Araştırmanın bir diğer bulgusunda Alt boyutlar ile kullanım süre değişkeni arasında anlamlı bir ilişki bulunmamıştır $(\mathrm{P}>0,05)$. $\mathrm{Bu}$ sonucun nedenini; teknolojik gelişmelerin çok değişkenli olup etkileri kullanım türü, şekli, çeşidi, süresi ve sıklı̆̆ıyla birlikte kullanan kişilerin bireysel özelliklerine de bağl1 olabilir (Mustafaoğlu, Zirek, Yasacı ve Özdinçler, 2018).

Bilgisayar Kullanma Becerisi alt boyutu ile Ortalama değişkeni arasında pozitif yönde anlamlı bir ilişki bulunmuştur $(\mathrm{P}<0,05)$. Bu sonuca göre; akademik başarısı yüksek olan öğrencilerin bilgisayar kullanma becerilerinin daha yüksek olduğu gözlemlenmiştir (Tablo 7). Literatürde; teknolojinin eğitim amaçlı kullanımının okul başarısını olumlu şekilde etkilediğine yönelik çalışmalar bulunmaktadır. Fakat teknolojinin eğitim amacı dışında kullanılması sonucunda ise okul başarısının negative yönde etkilendiğini vurgulayan çalışmalarda mevcuttur. Çünkü; teknolojik gelişmeler, pozitif etkilerine karşın, geçmişte olmayan internet bağımlılı̆̆1, telefon bağımlılığı veya oyun bağımlılığ değişkenler öğrencilerin akademik başarısını olumsuz etkilemektedir (Elmas, Kete, Hizlısoy ve Kumral, 2015; Mustafaoğlu ve diğerleri, 2018; Bülbül ve Tunç, 2018, Kuyucu, 2017).

Üniversite öğrencilerinin bilgi ve iletişim teknolojilerine adaptasyonu sürecinde özellikle Web 2.0 teknolojileri önem kazanmaktadır (Usluel, 2007). Dokuz Eylül Üniversitesinde okuyan 2776 öğrencisi üzerinde yapılan çalışmaya göre Web 2.0 teknolojilerinden özellikle sosyal paylaşım temelli ağlarda (anında mesajlaşma, video paylaşımı gibi) diğer teknolojilere kıyasla öğrencilerin adaptasyonunu kolaylaştırdığ 1 sonucuna varılmıştır (Baran ve Ata, 2013). Bu sosyal paylaşım ağlarını üzerinden tasarlanmış eğitim ortamları, üniversite öğrencilerinin eğitimine yönelik akademik ve idari bilgilerle daha etkin biçimde ilgilenecekleri söylenebilir.

Spor Bilimleri Fakültesi öğrencilerinin teknoloji kullanımını arttırmada ve eğitimlerine yardımc1 olması konusunda teşvik edici unsur olarak sosyal paylaşım ağlar1 ve/veya buna benzer ortamlar oluşturulabilir. 93 öğretmen adayı üniversite öğrencileri üzerinde yapılan bir çalışmaya göre, öğrencilerin neredeyse \%86's1 öğretmen olduğunda bilgisayarı dersin ana ekipmanı olarak çok yoğun bir şekilde kullanmayı istediklerini söylemişlerdir (Fisher, 2006).

Sakarya Üniversitesinde okuyan 282 öğrenci üzerinde yapılan bir çalışmaya göre, öğrencilerin bilgisayar ve teknoloji kullanımı kolaylıkla geliştirmeleri için evlerinde bilgisayar bulundurmaları gerektiğini, bu konuda ebeveynlerini yaşam boyu öğrenme kursları ile desteklemesi gerektiği sonucuna varılmıştır. Okul bilgisayar laboratuvarlarının daha aktif kullanılmasının öğrencilerin teknoloji kullanımlarını geliştireceği düşünülmektedir (Güçlü, 2010).

Öğrencilerin kariyer hedeflerine ulaşmada teknoloji kullanımı oldukça önemli bir yer kaplamaktadır. 17 Flaman okulu (sanat okulu) ile yapılan ve 2973 kişiye uygulanan çalışmaya göre Endüstri Bilimi, inşaat ve ahşap bölümlerini seçen 2. Sınıf öğrencilerinin teknolojiye akranlarına göre 
daha çok ilgi gösterdiğini, teknoloji ile ilgili daha büyük kariyer hedefleri olduğunu ve teknoloji konusunda daha az endișeli oldukları bulmuştur (DeAndrea, Ellison, LaRose, Steinfield ve Fiore, 2011).

Sonuç olarak; lisans öğrencilerini teknolojiye adapte etmek için eğitim hayatları boyunca teknoloji ve bilgisayar kullanımına daha fazla yer verilmesi ve üniversite bilgisayar laboratuvarlarının daha etkin kullanılması gerektiği düşünülmektedir. Eğiticilerin aynı şekilde teknolojik imkanlardan faydalanarak derslerini yürütmesi öğrenciler için iyi bir örnek ve aynı zamanda motive edici nedenlerden biri olduğu söylenebilir.

\section{KAYNAKÇA}

Akkoyunlu, B. (1995). Bilgi Teknolojilerinin Okullarda Kullanımı ve Öğretmenler Rolü. Hacettepe Universitesi Eğitim Fakültesi Dergis, 105.

Akpınar, Y. (2005). Bilgisayar Destekli Eğitimde Uygulamalar. Ankara: Anı Yayınları.

Aksüt, M. (2005). "Eğitim Fakültesi Öğrencilerinin Ödev Hazırlamada İnternet Kullanımına İlişsin Tutumları. (s. 77). İstanbul: Türkiye İnternet Konferans1.

Aktaş, E., Balkan, B., ve Karapınar, K. (2009). Biga'da Bilişim Teknolojileri Kullanımının Öğrenci Başarı ve Harcama Düzeylerine Olası Etkileri. Kocaeli Üniversitesi, İktisadi ve İdari Bilimler Fakültesi Dergisi, 41-48.

Aktaş, E., Tuncer, İ., ve Kıran, B. Mersin Üniversitesi Öğrencilerinin Bilişim Teknolojisi Kullanımının Harcama ve Eğitim Düzeylerine Etkileri. Dünya İnsan Bilimleri Dergisi, 2020(2), 45-69.

Aydemir, M., Küçük, S., ve Karaman, S. (2012). Uzaktan Eğitimde Tablet Bilgisayar Kullanımına Yönelik Öğrenci Görüşlerinin İncelenmesi. Eğitim ve Öğretim Araştırmaları Dergisi, 153-159.

Aycan, A., ve Üzüm, H. (2020). The effects of sports participation on internet addiction of high school students. Journal of Human Sciences, 17(4), 1022-1033.
Baran, B., Ata, F. (2013). Üniversite Öğrencilerinin Web 2.0 Teknolojileri Kullanma Durumları, Beceri Düzeyleri ve Eğitsel Olarak Faydalanma Durumları. EĞíTiM VE BİLIM, [S.1.], v. 38, n. 169, aug. 2013. ISSN 1300-1337.

Bülbül, H., ve Tunç, T. (2018). TELEFON VE OYUN BAĞIMLILIĞI: ÖLÇEK INCELEMESİ, BAŞLAMA YAŞI VE BAŞARIYLA İLIŞKİSI. Visionary EJournal/Vizyoner Dergisi, 9(21).

Bozcan, Ü. E. (2010). Eğitim öğretim faaliyetlerinde teknoloji kullanımı. Eğitim Teknolojileri Araştırmaları Dergisi, 1(4), 1-13.

Cantürk Günhan, B., Başer, N., ve Yavuz, C. (2008). Sinıf Öğretmenliği Öğretmen Adaylarının Bilgisayara Yönelik Tutumlarının Belirlenmesi ve Demografik Özelliklerine Göre Karşılaştırılması. I. Uluslar Arası Bilgisayar ve Öğretim Teknolojileri Sempozyum Bildirisi, (s. 1370-1383).

Çavaş, B., Kışla, T., ve Twining, P. (2004). Eğitimde Bilgi ve İletişim Teknolojilerinin Kullanımına Yönelik Bir Araştırma: dICTatEd Yaklaşımı. 6.Akademik Bilişim Konferansı. Trabzon: Akademik Bilişim Konferans1 ve İnternet Teknolojileri Derneği.

Çelik, H. Ç., ve Bindak, R. (2005). Lise Öğrencilerinin Matematik ve Bilgisayar Tutumlarının Çeşitli Değişkenler Açısından Karşılaştırılması. Pamukkale Üniversitesi Eğitim Fakültesi Dergisi.

Çevik Kılıç, D. B. (2015). Müzik Öğretmeni Adayların. Balıkesir University The Journal of Social Sciences Institute, 26.

Çakmak, T., ve Yalçın, H. (2013). Üniversite öğrencilerinin mobil teknoloji kullanımı: Hacettepe üniversitesi bilgi ve belge yönetimi bölümü örneği. Hacettepe Üniversitesi Türkiyat Araştırmaları (HÜTAD), 18(18), 47-61.

Demir, N., ve Büyükalan Filiz, S. (2018). Kamu Çalışanlarının Bilgi ve İletişim. Sayıştay Dergisi Say1108, 151.

Demirli, C., ve Dikici, A. (2003). Öğretimde Web Tabanlı Uygulamaların Öğrenci Başarısına Etkisi. Third International 
Education Technologies Symposium. KKTC.

Devecioğlu, S., ve Şimşek, A. (2018). Spor Endüstrisinde Yeni Teknolojilerin Görünümü. Uluslararası Beden Eğitimi Spor Rekreasyon ve Dans Dergisi, 20-36.

Elmas, O., Kete, S., Hizlısoy, S. S., ve Kumral, H. N. (2015). Teknolojik cihaz kullanım alışkanlıklarının okul başarısı üzerine etkisi. SDU Journal of Health Science Institute/SDÜ Saglik Bilimleri Enstitüsü Dergisi, 6(2).

Hunt, N. P., ve Bohlin, R. M. (1993). Teacher Education Student' Attitudes. Journal Research on Computing in Education, 487-497.

Jan Ardies • Sven De Maeyer • David Gijbels • Hanno van Keulen nt J Technol Des Educ (2015) 25:43-65 DOI $10.1007 / \mathrm{s} 10798$ $014-9268-\mathrm{x}$

Karasar, N. (2015). Bilimsel Araştırma Yöntemleri. Nobel Akademik Yayıncılık.

Kolburan Geöer, A., ve Dağ, F. (2010). Üniversite Öğrencilerinin Bilgisayar Okur-yazarlık Düzeylerinin Belirlenmesi: Kocaeli Üniversitesi Örneği. Yüzüncü Yll Üniveritesi Eğitim Fakültesi Dergisi, 2044.

Krueger, K., Hansen, L., ve Smaldino, S. (2000). Preservice teacher technology competencies: A model for preparing teachers of tomorrow to use technology. TechTrends, 47-50.

Kuyucu, M. (2017). Gençlerde akıllı telefon kullanımı ve akıllı telefon bağımlılığı sorunsal1:"Ak1llı telefon (kolik)" üniversite gençliği. Global Media Journal TR Edition, 7(14), 328-359.

Güçlü M. (2010). The Turkish Online Journal of Educational Technology - April 2010, volume 9 Issue 2

Mercedes Fisher (2000) Computer skills of initial teacher education students, Journal of Information Techology for Teacher Education, 9:1, 109-123, DOI: 10.1080/14759390000200075

Mustafaoğlu, R., Zirek, E., Yasac1, Z., ve Özdinçler, A. R. (2018). Dijital teknoloji kullanımının çocukların gelişimi ve sağlığı üzerine olumsuz etkileri. Addicta: The Turkish Journal on Addictions, 5(2), $1-21$.

Özen, G., Güllü, M., ve Uğraş, S. (2016). Beden Eğitimi Öğretmenlerinin Beden Eğitimi Dersiçi ve dışı Etkinliklerinde Teknolojik Araç ve Gereçlerin Kullanımıyla İlgili Görüşleri. Gaziantep Üniversitesi Spor Bilimleri Fakültesi, 24-37.

Özmusul, M. (2008, Temmuz). İlköğretim İkinci Kademe Öğrencilerinin Bilgi ve İletișim Teknolojilerinden Yararlanma Düzeylerinin İncelenmesi (Kilis İli Örneği). Yüksek Lisans Tezi. Gaziantep, Türkiye: Gaziantep Üniversitesi.

Palao, J., Hastie, P., Ortega, E., ve Cruz, P. G. (2015). The Impact of Video. Technology,Pedagogy and Education, 5163.

Shapkaye, J., ve Ferrari, M. (2003). Computerrelated attitudes and actions of teacher candidates. Computers in Human Behaviour, 319-334.

Som, S., ve Kurt, A. A. (2012). Media literacy levels of students attending the department of computer education and instructional technologies. Anadolu Journal of Educational Sciences International, 2(1), 104-119.

Tecim, V., ve Göksen, Y. (2009). Bilișim Teknolojilerinin Üniversitelerde Etkin Kullanımı Üzerine Bir Çalıșma. Journal of Yasar University, 2237-2256.

Tosun-Tunç, G., ve Sevilmiş, A. (2019). Sporda İnovasyon: Bir Derleme Çalışması. Türk Spor Bilimleri Dergisi, 39-46.

Uşun, S. (2013). Bilgisayar Destekli Öğretimin Temelleri. Ankara: Nobel Akademik Yayıncilik.

Visscher, A., Wild, P., Smith, D., ve Newton, L. (2003). Evaluation of the Implementation, use and Effects of a Computerised Management Information System In English Secondary Schools. British Journal of Educational Technology, 357366.

Yakar, M., ve Orhan, O. (2016). Investigating Land Surface Temperature Changes Using Landsat Data in Konya, Turkey. Proceedings of The International Archives of Photogrammetry, Remote Sensing and 
Spatial Information Sciences, 16(6), 12-

19.

Yaman, M., ve Yaman, Ç. (2008). Beden Eğitimi Ve Spor Bölümü Öğrencilerinin. Akademik İncelemeler, 4.

Yeşilyurt, S., ve Gül, Ş. (2007). Bilgisayar Kullanma Becerileri ve Bilgisayara Yönelik Tutum Ölçeği (BKBBYTÖ) Geçerlik ve Güvenirlik Çalışması. Ondokuz Mayıs Üniversitesi Eğitim Fakültesi Dergisi, 79-88.

Y1ldırım, İ. (2015). A study on physical education teachers: The correlation between selfefficacy and job satisfaction. Education, 135(4), 477-485.

Y1lmaz, İ., Ulucan, H., ve Pehlivan, S. (2010). Beden Eğitimi Öğretmenliği Programında Öğrenim Gören Öğrencilerin Eğitimde Teknoloji Kullanımına İlişkin Tutum ve Düşünceleri. Ahi Evran Üniversitesi Eğitim Fakültesi Dergisi, 105-118.

Yuen, A., ve Ma, W. (2002). Gender Differences in Teacher Computer Acceptance. J1. of Technology and Teacher Education, 365382.

Yücel, A. S., ve Devecioğlu, S. (2011). Spor Eğitiminde Bilgi ve İletişim Teknolojilerinin. 5th International Computer \& Instructional Technologies Symposium (s. 2). ELAZIĞ: Firat Üniversitesi.

Yücel, A. S., ve Devecioğlu, S. (2012). Spor Eğitiminde Bilgi ve İletişim Teknolojilerinin Kullanımı. e-Journal of New World Sciences Academy NWSASports Sciences, 1-17.

Yüksel, F. (2005). Bilgi Teknolojileri ve Yerel Yönetimler. SÜ İİF Sosyal ve Ekonomik Araştırmalar Dergisi, 247. 